\title{
Na parábola do desvalido no caminho (LC 10, 25-37): 0 autoconceito pela humanização em saúde
}

\author{
The parable of the helpless man at the roadside (Lk 10, 25-37) \\ according to the self-concept in health humanization
}

\section{Ramiro Délio Borges de Meneses}

Mestre em Bioética Teológica, pela Faculdade de Teologia da Universidade Católica Portuguesa (UCP), lecciona no Instituto Politécnico de Saúde do Norte (Gandra e Famalicão) e no Instituto Superior de Ciências da Saúde do Norte - Gandra; investigador sénior do Instituto de Bioética da Universidade Católica Portuguesa - Centro Regional do Porto; Investigador do Centro de Estudos Filosóficos da Faculdade de Filosofia - Centro Regional de Braga, UCP - Portugal, email: borges272@gmail.com

\section{Resumo}

Com este texto procuramos uma leitura do pensamento de W. James sobre o self (autoconceito) no âmbito da parábola do bom samaritano (Lc 10, 25-37). Aqui, encontramos uma original forma de abordar o sentido da humanização, em saúde, pelos fundamentos antropológico-bíblicos do autoconceito e a forma como este se vivencia no âmbito da mesma humanização em saúde. Naturalmente, o "autoconceito" está presente, nessa parábola, sob a forma de um "acolhimento esplancnofânico" na vida de um desvalido no caminho. O samaritano faz um "mim agápico" ao Homo Viator, dado este que determina um “mim soteriológico” pela misericórdia de Deus-Pai. Variados são 
os "mim” na parábola, a começar pelo mim material, representado nos salteadores, passando ao "mim litúrgico", que tem o sentido na dimensão do "mim de identidade", referido nas personagens do sacerdote e do levita. Um dos elementos fundamentais, presentes na parábola do desvalido no caminho, radica no "mim social", que se referem em dois árbitros, que salientam o sentido do "mim de identidade", referenciados nos personagens fictícios: sacerdote e levita. Assim, a parábola apresenta uma nova concepção do sentido do autoconceito na vida de um desvalido no caminho pela acção agápica de um samaritano bom. 0 “mim" espiritual e o “mim” social conferem um sentido pastoral à parábola do bom samaritano, em virtude da "deliberação esplancnofânica" do samaritano perante o desvalido no caminho.

Palavras-chave: Parábola do bom samaritano. Autoconceito. Mim. W. James. Humanização em saúde e bioética.

\section{Abstract}

This text approaches the thought of W. James about the "self" in the context of the parable of the good Samaritan (Lk 10, 25-37). Here we find an original way to address the sense of humanization, health, anthropological and biblical foundations for the "self" and how it is experienced within the same health humanization. Of course, the "self" is present, in this parable, in the form of a "splancnophanic host" in the life of a helpless man at the roadside. The Samaritan is an "agape me" to the Homo Viator, because this determines a "soteriological me" by the mercy of God the Father. The "me" in the parable are varied, starting with "material me", represented by the robbers, and the "liturgical me", which has the dimension of its meaning in "identity me", represented by the characters of the priest and the Levite. One of the key elements presented in the parable of the helpless man at the roadside lies in the "social me", referring to two referees, who underline the sense of "identity me" referenced in the fictional characters: the priest and the Levite. Thus, the parable presents a new conception of the sense of the "self" in the life of a helpless man at the roadside by means of the agape action of a good Samaritan. The spiritual "me" and the social "me" give a pastoral sense to the parable of the good Samaritan, because of the splancnophanic deliberation of the Samaritan towards the helpless man.

Keywords: The parable of the good Samaritan. Self-concept. Self. Bioethics. W. James. Health humanization. 


\section{Introdução}

W. James deu um contributo elevado para o desenvolvimento da teoria do "autoconceito". O filósofo pragmático, no seu trabalho de 1890, introduziu o conceito do Eu e do autoconceito. Assim, a forma como uma pessoa se concretiza, a respeito de si mesma, depende daquilo que aceita "ser e fazer". Dessa forma, o contributo de W. James é fundamentado pela distinção que elabora entre o "mim" e o "Eu". Para esse filósofo, é o "Eu" que tem consciência do "mim". Procura-se, pelo pensamento de James, fazer uma leitura da parábola do bom samaritano. Alcântara afirmara que a autoestima valoriza, no indivíduo, aquilo que há de positivo e negativo. Logo, surge a distinção entre o favorável ou desfavorável, o agradável ou desagradável, que a pessoa vê em si (ALCÂNTARA, 1997, p. 10-13).

$\mathrm{Na}$ verdade, chegamos ao cerne da autoestima. É na valorização, no sentimento, na admiração ou desprezo, no afecto, no gozo ou dor íntima, que se condensa a "quinta essência" para Alcântara (SERRA, 1986, p. 67-84). Segundo esse autor, estamos a um passo do "amarás o próximo como a ti mesmo". Isso significa que devemos amarmo-nos a nós próprios. Um amor e uma estima a nós mesmos, porque só assim a pessoa se desenvolverá e realizará. Daqui se infere que a essência da pessoa não se pode compreender, de um modo estático, mas de modo dinâmico, isto é, como origem do seu agir e da sua própria realização. Na autoestima, a humanização, em saúde, encontra-se numa avaliação positiva, que permite ao clínico e ao doente alcançar objectivos desejados, obter reforços e evitar o fracasso.

$\mathrm{Na}$ humanização, há uma avaliação que a pessoa (clínico/doente) faz de si, de uma dada aptidão, da sua capacidade ou das suas acções, não se limitando só ao espaço da própria avaliação. Assim, ultrapassa-o e dá origem ao sentido de competência ou da eficácia pessoal. A humanização implica a autocompetência como fenómeno básico, centrado na eficácia da pessoa para regular os acontecimentos da vida (SERRA, 1986, p. 57-66).

Na humanização, em saúde, define-se a "autoeficácia" como o nível de competência de um indivíduo. As experiências de sucesso, quando se realiza determinada tarefa (Aufgabe), tal como sucedeu com o bom samaritano, podem constituir a variável mais influente na determinação do grau da sua 
execução perante o desvalido no caminho. A humanização em saúde vive do "mim", e deste se alimenta, desenvolvendo-se pelo "autoconceito" (self).

Assim, as pessoas competentes são mais activas e determinadas nos seus objectivos, tal como se aufere do paradigma do bom samaritano. Porém, tal como se reflecte no sacerdote e no levita, as pessoas que se consideram menos competentes são as mais hesitantes na percepção dos seus objectivos. Essas pessoas poderão muito facilmente demitir-se dos seus objectivos e desistir das "tarefas" prematuramente, tal como sucede na desumanização.

Quando na humanização, em saúde, se desiste de objectivos, confirma-se a avaliação da incompetência. O autoconceito "competência" não é a mesma coisa que comportamento competente. Os aspectos comportamentais da competência envolvem pautas activas, adaptadas ao ambiente na procura de objectivos pessoais (HATTIE, 1992, p. 25-46).

Wells e Marswel asseveram que há dois aspectos de "autoestima", uma baseada num sentimento de competência ou eficácia, e outra fundamentada na virtude ou nos valores morais (BOLANDER, 1986, p. 1748).

A humanização pelo autoconceito (self), baseada na virtude, está patente no agir responsável do bom samaritano diante do desvalido no caminho, porque representa o valor pessoal e está relacionada com normas e valores respeitantes ao comportamento pessoal e interpessoal, em termos de reciprocidade, justiça, honra e, sobretudo, misericórdia.

Com efeito, no âmbito de humanização pelo autoconceito, clarificam-se quatro grandes componentes da autoestima: competência, importância, coerência e poder. ${ }^{1}$ Assim, a autoestima assume um importante papel na percepção dos acontecimentos, na interpretação e posterior desenvolvimento nas acções das pessoas, tal como se induz nas pautas de comportamento externas e internas, definidas ora pelo "semivivo", ora pelo bom samaritano. ${ }^{2}$

1 A competência é a capacidade de realizar, com êxito, os próprios objectivos, sendo designada por autoeficácia. A importância surge como um sentimento de ser aceite e respeitado. Com efeito, a coerência ajuda de acordo com as próprias crenças e valores. Finalmente, o poder aufere-se como habilidade para influenciar os outros.

2 Coopersmith defende que uma autoestima elevada reúne as características seguintes: activa, bem sucedida, espontânea, autoconfiante, optimista [KENDLER, H. H. Introdução à psicologia. Lisboa: F. C. Gulbenkian, 1985. v. II, p. 230-240]. Todos esses predicados se encontram no ethós da humanização, nos cuidados de saúde. Daqui que essas qualidades de "autoestima" surgem, metaforicamente, no Bom Samaritano, porque são efeitos da misericórdia.

Rev. Pistis Prax., Teol. Pastor., Curitiba, v. 3, n. 2, p. 557-570, jul./dez. 2011 
Logo, a "autoestima" assume um papel importante na vida das pessoas, segundo Alcântara, e, ainda, influencia vários aspectos da humanização. Condiciona a aprendizagem, ajuda a superar as dificuldades e fundamenta a responsabilidade, isto é, apoia as pessoas a serem responsáveis, capazes e dispostas a comprometerem-se, apoiando a criatividade. Segundo Alcântara, a autoestima manifesta-se como atitude para comigo próprio. A humanização é adquirida na relação médico-doente e ocorre como resultado da história de cada um desses sujeitos. A humanização em saúde é o resultado de uma longa e permanente sequência de acções, que se vão conformando no decurso da vida clínica ${ }^{3}$ e que surgem da interioridade.

Segundo o referido pensador, o componente comportamental ou conduta significa tensão, intenção e decisão de agir ao conduzir a prática de pautas, tal como se verifica na humanização. Daqui surge a autoafirmação dirigida para o Eu e em busca de consideração e reconhecimento por parte dos outros (ALCÂNTARA, 1997, p. 13).

A humanização moralmente refere-se na relação e no esforço para obter estima, honra e respeito por parte dos outros (semivivo) e de nós próprios (samaritano). Porém, a moldagem do autoconceito é exequível até determinada altura da vida da pessoa. Na humanização, a partir do momento em que se forma um esquema de autorregulação, a mudança não é fácil, embora seja possível, podendo originar a desumanização.

3 A humanização é o resultado de uma longa e permanente sequência de acções que se são adequatio ao decurso da vida intersubjectiva de doentes e médicos. A humanização é uma realidade consistente, difícil de remover e de mudar, mas não é estática, pode crescer, arraigar-se intimamente, ramificar-se e interligar-se noutras atitudes ou pode debilitar-se, empobrecer-se ou desintegrar-se. A humanização é uma forma radical de ser e de actuar. É a razão da conduta do indivíduo, mas não é a própria conduta, mas um somatório de condutas interpessoais. É determinante para o comportamento e surge como princípio e fim da acção humana.

A humanização possui duas qualidades: a transferência e a generalização. A partir da unidade destas, abrese a um elenco multiforme de condutas. Dialecticamente, a humanização vive numa morada da conduta (ethos), fala pelo discurso clínico (logos) e sente-se no sofrimento do doente (pathos), da forma seguinte:

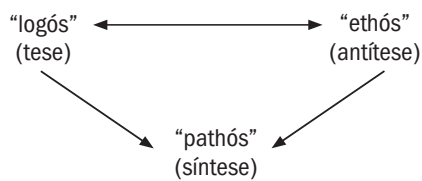

Segundo a humanização, a autoestima não se limita à própria avaliação, determina comportamentos do doente (representado pelo semimorto da parábola) e dos clínicos (representado simbolicamente pelo Bom Samaritano). 
Devemos relembrar que o autoconceito é a percepção que um médico/doente tem de si, de tal forma que deve salientar que a formação dessas percepções se determina pelos seguintes denominadores: experiências e interpretações; esforços e avaliações de pessoas (doentes e médicos).

Assim, Shavelson e colaboradores concluíram que o autoconceito se referencia como construto hierárquico e multifacetado, e daqui surgem os seguintes predicados: organizado ou estruturado em categorias; multicêntrico e hierárquico (HATTIE, 1992, p. 76).

A humanização, pelo autoconceito, implica uma organização hospitalar, uma configuração multifacetada de comportamentos e as percepções dos comportamentos das pessoas ou situações clínicas que estão na base da hierarquia. A noção de hierarquia no autoconceito é universal. Richlack defendeu que um conceito hierárquico é imediatamente sugerido quando se pensa nas propriedades particulares, cada uma das quais pertencente a uma classe muito abstracta de formas universais.

O autoconceito evolui, isto é, tende a tornar-se multifacetado à medida que a pessoa evolui, o que implica uma forma de orientar a humanização.

No domínio da humanização, pelo autoconceito, aquele que se reveste de relevância encontra-se na dimensão social. Este originou-se quando W. James escreveu: "O mim social de um homem é a consideração que ele obtém no seu meio. Não somos somente animais que vivem em grupo e que gostam de se encontrar entre os seus semelhantes, temos uma tendência inata para querermos ser notados e a nosso favor". 4

Segundo W. James, em 1890, introduziu-se a ideia do Eu e do autoconceito. E observou-se que a forma como uma pessoa se sente a respeito de si própria depende inteiramente daquilo que aceita ser e fazer.

Logo, a contribuição de W. James é importante pela distinção que faz entre o "mim" e o "Eu" (I-self and Me-self), afirmando que, ao mesmo tempo, penso e tenho mais ou menos consciência de mim, da minha existência pessoal. Para esse filósofo, é o Eu que tem consciência do mim.

4 "A man's social self is the recognition which he gets from his mates. We are not only gregarious animals, liking to be in sight of our fellows, but we have an innate propensity to get ourselves noticed, and noticed favorably, by our Kind" [JAMES, W. Principles of psychology. Toronto: York University, 1890, p. 2-3]. 
Assim, seria como se a personalidade total fosse dupla, sendo, ao mesmo tempo, o "sujeito conhecedor" e o "objecto conhecido". Para W. James, o self do homem é a soma total de tudo o que ele pode chamar de seu. ${ }^{5}$

Enquadrado no pensamento do filósofo do self, o "Eu" representa-se no "semimorto" e o samaritano é o "mim", do material ao espiritual. O autoconceito (self) faz-se pela conjugação dos três "mim". Logo, a humanização em saúde vai do "mim" material ao "mim" espiritual, passando pelo social. ${ }^{6}$ O "mim" material encontra-se simbolizado no sacerdote e no levita, dado que a sua atitude refere o comportamento das preferências instintivas, em que se encontram as nossas razões práticas do viver. O "mim social" representa a honra e atendimento do estalajadeiro.

Porém, o "mim" espiritual é expresso pelo comportamento exemplar do samaritano, em que se mostra a "consciência da actividade" responsável, como centro da ternura. O samaritano está diante do Ego purus, que lhe faz remover as vísceras, "Jesus Cristo, como desvalido no caminho para a Cruz" como supremo autoconceito de Deus-Pai, ao cumprir a sua vontade.

Segundo W. James, o autoconceito social induz a avaliação das competências da pessoa ou de grupos específicos de outras pessoas. Após a análise dos elementos do "mim", W. James reflectiu sobre os sentimentos e as emoções que aquele proporciona, isto é, a "consciência do valor do mim" (JAMES, 1890, p. 10-15).

5 W. James estudou estes dois aspectos, designando o "mim" por objecto conhecido como o "mim" empírico, como é conhecido; o Eu como sujeito do ego purus e o "mim" como personalidade empírica. 0 "mim" é considerado segundo três perspectivas: os elementos integrantes do "mim"; os sentimentos e as emoções, que desencadeiam a consciência do valor do "mim", e as reações que provocam, isto é, a procura e a defesa do "mim". Os elementos integrantes do "mim" são o material, o social e o espiritual.

60 "mim" material revela-se, no corpo, como elemento central. Os outros elementos do "mim" material são a família, o nosso próximo, etc. 0 "mim" social será a consideração que se obtém no seu meio, ou seja, 0 reconhecimento de ter alguns amigos. 0 homem mostra-se sob ângulos especiais em cada um dos grupos em que se encontra. A reputação e a honra são nomes dos "mim" sociais, tal como sucedeu pelo comportamento do sacerdote e do levita na parábola. Finalmente, o "mim" espiritual, que pertence à personalidade empírica, será o ser interno e subjectivo, que contém as faculdades ou disposições, que são as partes mais íntimas do self. Neste, há diversos graus de interioridade, das emoções às paixões. Segundo W. James, a "consciência da nossa actividade" é o que há de mais central no "mim" espiritual, sendo o coração de toda a personalidade empírica, o santuário mais íntimo do homem. [JAMES, W. Self concept. Hillsdade: Lawrence Erlbaum Associates, 1992, p. 232].

Rev. Pistis Prax., Teol. Pastor., Curitiba, v. 3, n. 2, p. 557-570, jul./dez. 2011 
Essa consciência, segundo o pensador, reveste-se de duas formas fundamentais: satisfação ou descontentamento. Existem sinónimos para designar essas duas formas de consciência afectiva do nosso valor: por um lado, a vaidade, o amor próprio, a arrogância - representada, na parábola, pelo sacerdote e pelo levita - e, por outro, a humildade, a modéstia, a contrição e a ternura - que são o apanágio da conduta do samaritano, que encontra o "Eu-puro" (desvalido) pelo caminho da consciência axiológica. Para W. James, o self do homem é a soma total daquilo que ele pode chamar como seu corpo, as suas faculdades psíquicas, as suas roupas, a sua casa, a mulher e os filhos, seus ancestrais e amigos, a sua reputação, etc. W. James apresenta o "mim" segundo três perspectivas como elementos integrantes. Os elementos integrantes do "mim" referem-se como o "mim" material, o "mim" social e o "mim" espiritual.

Para W. James, o "mim material" radica no corpo, sendo o elemento central do "mim" material, como as coisas, posse de bens ou a casa. Por causa das preferências institutivas, encontramos, por meio do "mim" material, as verdadeiras razões práticas do viver, que se poderão exprimir em processos conjuntivos e/ou disjuntivos do nosso existir. Pela parábola, metaforicamente, o "mim material" encontra-se vivenciado pelos salteadores, que somente se preocupavam com bens materiais, dado que terminaram por deixá-Lo como "semimorto". O desvalido no caminho (Lc 10,30) ficou fragilizado pelo "mim” material. Esta será a consideração que ele obtém no seu meio, ou seja, o reconhecimento de alguns amigos. Segundo W. James, um homem tem tantos "mim" sociais" quanto indivíduos que o conhecem ou têm dele uma ideia ou opinião. A reputação e a honra são nomes dos "mim" sociais. O paradigma do "mim" social realiza-se no comportamento do sacerdote e do levita, que só se preocupavam com a reputação e honra, mais do que servir o desvalido no caminho. O sacerdote e o levita (Lc 10,31-32) estavam preocupados com o culto do Templo de Jerusalém e com o cumprimento da Torah, que dava estatuto social e honra perante as classes sociais e o regime político. Ao passarem para o outro lado do caminho, marcaram presença como um "mim" social. Este aspecto foi mais relevante do que tratar de um desvalido, com necessidades, sem valor perante o "mim" social. Este "mim" radica na personalidade empírica. Surge como um ser interno ad intra e subjectivo, que contém as 
faculdades psíquicas ou disposições, que são as partes mais resistentes e íntimas do self. Aqui existem diversos graus de interioridade, como as emoções, os desejos e os momentos profundos, que percepcionamos do mundo exterior.

O "mim" espiritual encontra-se representado por meio do samaritano, que O viu, aproximou-se d'Ele, porque "se comoveram as vísceras". Seguidamente, prestou-lhe "cuidados", permitindo restaurar o "semimorto", com a ajuda do estalajadeiro. Se, segundo W. James (1890), a consciência da nossa actividade é o que há de mais central no "mim" espiritual, então é como se conhece. É o coração da personalidade empírica o santuário mais íntimo da vida no homem.

O samaritano vive nessa forma de "consciência", muito embora esta se faça não ad intra, como salienta W. James (1890), mas ad extra, porque Dei misericordiae eventum. Depois de analisar os elementos do "mim", W. James elabora os sentimentos e as emoções que o Eu determina. Pela leitura de W. James, poderemos dizer que o "Eu supremo" se exprime, metaforicamente, no quidam homo, que será o "semimorto" (Lc 10, 33). Tal como no pensamento de W. James, o Eu é a consciência enquanto tal, os "mim" não são senão diferentes objectivos de que tenho consciência. Por outras palavras, o Eu é o que pensa em nós. O Eu supremo representaria o "meio-morto", que está presente na última viagem para Jerusalém (Lc 9, 51, 11).

Entretanto, o "mim" espiritual participa do "eu absoluto", que está como desvalido, segundo a parábola do bom samaritano. Para W. James, o "mim" espiritual caracteriza-se por alguns componentes da vida empírica, tais como: aspirações intelectuais, morais e religiosas, bem como o instinto moral e os sentimentos de superioridade moral ou intelectual. Esses elementos aretológicos cabem na imagem e na semelhança do samaritano.

A procura da análise dos sentimentos e emoções que o "mim" determina, isto é, a consciência do valor do "mim", está presente na vida do Eu. Assim, a consciência reveste-se de duas formas fundamentais: satisfação e descontentamento de si. Existem sinónimos para designar essas duas formas da consciência, que aparecem pelo orgulho, presunção, vaidade e amor próprio, arrogância e vanglória, e que possuem o seu 
enquadramento e vivência no sacerdote e no levita (Lc 10, 31-32). Mas a modéstia, a humildade, a contrição e o sentimento de ajuda espelham-se na conduta do samaritano (Lc 10, 33-35). Estas são as virtudes que surgiram a partir da "comoção das vísceras" (Lc 10,33). O "mim" espiritual, pela consciência, vivencia-se nessa forma aretoaxiológica. Os salteadores (Lc 10, 30) estavam satisfeitos consigo próprios. Os sentimentos não são determinados, são antes normalmente provocados pelos sucessos e insucessos, pela boa ou má posição no mundo. Esses sentimentos também aparecem nas vivências do sacerdote e do levita (Lc 10, 31-32).

Será necessário salientar os actos por meio dos quais o "mim" tende a proporcionar o sentimento de satisfação de si e a soma dos pesares, como sentimento oposto, isto é, de "desonra", tal como se justifica na conduta não exemplar dos salteadores, que viveram de si e para si. Os salteadores (Lc 10, 30) estavam satisfeitos consigo próprios. Os sentimentos não são determinados. Esses sentimentos também aparecem nas vivências do sacerdote e do levita (Lc 10, 3 1-32). Será necessário salientar os actos por meio dos quais o "mim" tende a realizar-se. O filósofo W. James enumera um grande número de instintos fundamentais: instinto de conservação, de expansão e de defesa, que poderão conduzir ao amor e à procura do "mim" e que se podem examinar desde a aflição do "mim" físico até ao "mim" social. Ao falar dos salteadores, no âmbito do "mim" material, seguem-se o instinto de propriedade, o instinto de construção, os apetites e os instintos físicos, etc. Pela consciência do valor do "mim" material, os salteadores vivem entre o orgulho das riquezas e o receio da pobreza. Para terminar esse ponto, será necessário dizer que, segundo W. James, o Eu é consciente, enquanto que o "mim" serão os diferentes objectos de que tenho consciência. Por outras palavras, o "Eu"é o que pensa em nós. Será o que pensa como nós e o que vive em nós. Pela leitura de W. James, o"Eu" corresponde ao quidam homo, que está na berma da estrada (desvalido). Assim, o "mim" material" (salteadores), o "mim" social (sacerdote e levita) e o "mim" espiritual (samaritano) encontram-se no Eu consciente, que os determina no seu agir responsável.

A “conversão" é princípio epistemológico de autenticidade teológica. Em todo o tempo e lugar, a conversão é existencial para uma responsabilidade poiética (interpessoal). A conversão do Samaritano é afectada 
pelo viver e pelo conviver. A dita conversão começa a possuir, como ponto de arranque, a admiração misericordiosa, que, como na parábola (Lc 10, 25-37), passa do samaritano como caminho de misericórdia, cordial e práxica, sobre a miséria e a situação do "meio-morto", abrindo o coração às dificuldades do Outro. Quando não se percorre esse caminho, estamos fora da salvação (Mt 18, 23 ss). Assim, o "ver" será a entrada principal de contacto e a porta de conhecimento, de aproximação (proximidade) ou de irmandade. Alterar-se pelo Eu (samaritano) é o início de toda a alteridade, de toda a sabedoria e de todo o conhecimento socialmente imperativo. O lugar da epifânia do rosto do Outro é o pobre, o doente e o marginal. Tal como o desvalido da parábola (Lc 10, 25-37), o único lugar possível para a epifânia do Pai das misericórdias são aqueles que não são o sistema: o distinto do sistema, o doente, o pobre, o nu, o drogado, etc. A identificação de Jesus com o pobre (Mt, 25) não é uma metáfora, não é uma lógica, mas antes uma vivência plesiológica. O Deus da nossa consolação revela-se no pobre. A exterioridade escatológica do pobre, do doente, do marginal, entendida segundo uma economia teologal, situa-se como realidade histórica e como categoria epistemológica de uma ética de libertação.

O samaritano situa-se como próximo pela escuta da voz, pela voz do desvalido (pobre, doente) e sente-se interpelado, transtornado, convertido, responsável pela comiseração, ao saber sofrer com o Outro, perante a dor e o sofrimento, transformado em critério da apelação poiética. O “outro", como epifânia do rosto do desvalido, vive na relação plesiológica e converte a ratio totalizante da admiração em abertura responsável e solidária.

Viver para o Outro, qualquer que seja esse Outro, será precisamente e, sobretudo, porque não o merecemos. A conversão de um extremo, ao diametralmente oposto, assinala para a consciência a chegada de uma vida, revelada como forma plesiológica. Em virtude do que é "perto de mim", a primeira pessoa, primeira para mim, segunda pela gramática e pela conjugação, passa a ser, no espírito, a primeira. A do interlocutor (tu) passa a ser a primeira, absolutamente primeira para "mim", desalojando-me do meu egoísmo e ocupando o meu lugar. A parábola do Homo Viator determina a conversão de um samaritano a um desvalido, porque a "comoção das vísceras" surge da misericórdia de Deus-Pai. A leitura da 
parábola do bom samaritano, pelo pensamento de W. James, é pragmática, enquanto a leitura de Lévinas refere uma fenomenologia bíblica, definindo-se numa ética de alteridade.

\section{Conclusão}

Para W. James, o Eu é consciente, enquanto que o "mim" não é senão os diferentes sujeitos de que o Eu tem consciência. Assim, o Eu é que pensa em nós. Em sentido analógico, foi o desvalido no caminho que pensou no "mim" do samaritano. A resposta deste é humanizadora pelo "mim" espiritual, por meio da consciência do valor de mim, que se caracteriza pelos sentimentos da superioridade moral do samaritano.

A análise de W. James refere que a humanização em saúde se padroniza em componentes da vida empírica do "mim" e poderá trazer a desumanização hospitalar. ${ }^{7}$

Na verdade, a humanização apresenta-se como uma anabasis, sendo a catabasis revelada na desumanização, porque a primeira supõe um elenchós (argumento) e uma hipostasis (doente).

A humanização, pelo elenchós, vai do argumento semiológico até ao semiótico e pela hipostasis vai da terapia (serviço) à terapêutica (instrumentos de cura). Assim, a humanização é uma "ascensão" do doente para o sentido do Ser-saudável, que se manifesta na prova clínica e desaparece na desfiguração do "semivivo" do elenchós do bom samaritano. A humanização será um "Versuch des Auftiegs zum Sim des Gesund auf dem verantwortlischen Tätigkeit". A humanização é a "ascensão" do Ser-doente para o sentido do "bem-estar", do "bem-ser" e do "bem-agir". Segundo M. Scheler, a humanização em saúde é marcada, axiologicamente, pelo

\footnotetext{
70 amor de mim (tendências) vai do "mim" material (apatias e instintos, amor do companheiro, etc.) pelo "mim" social (desejo de agrado, sociabilidade, ambição, etc.) ao "mim" espiritual (aspirações intelectuais, instinto moral, vida religiosa, etc.). Mas possui um fundamento na consciência do valor de mim (sentimento), que quanto ao "mim" social se salienta na vaidade ou no orgulho, e que por este "mim" se encontra na glória fácil ou no senobismo, para terminar no "mim" espiritual, pelos sentimentos de superioridade intelectual ou moral. Se a humanização, segundo W. James, se encontra pelo "mim" espiritual, então verifica-se a desumanização em saúde pelo "mim" material.
}

Rev. Pistis Prax., Teol. Pastor., Curitiba, v. 3, n. 2, p. 557-570, jul./dez. 2011 
interesse soteriológico, porque se define pela forma como se dá a anabasis da pessoa doente, pelo seu amadurecimento e discernimento interiores. A humanização é uma ascensão do doente pelo autoconceito - este narra a percepção que doente e médico possuem de si próprios. O samaritano encontra o "desvalido" e ajuda-O nas suas necessidades e no seu sofrimento. Não espera pelo estalajadeiro e nem se limita a bons conselhos, mas assume a sua desgraça. Não calcula eventuais vantagens, e aquilo que fez, tê-lo-ia feito a qualquer outro. A relação é directamente subjectiva e passa para além de qualquer comunicação ou instituição. O que existiu foi um reconhecimento entre sujeitos, do qual se produz a comunidade entre eles, que passa pela comunhão de bens que eles têm - isto porque um tem bens e outro não os possui. Ocorre, a partir do reconhecimento entre os sujeitos, a identificação deles. O verdadeiro ponto de partida constitui a imaginação transcendental e a aproximação à realidade. A imaginação transcendental somente a podemos efectuar de forma apelativa. Esta é uma forma de linguagem que é própria da poiética. Pela "razão pragmática", segundo o pensamento de W. James, encontramos a parábola do bom samaritano como vivência empírica do "mim", que vai do material ao espiritual, passando pelo social. Certo é que a Parabola do Bom Samaritano implica, por um lado, uma "ética plesiológica" e, por outro, uma "ética poiética”, na qual, pela relação do samaritano e do desvalido, se justifica a razão e a consciência poiéticas. Um último elemento ético refere-se à responsabilidade poiética, caracterizada por um compromisso misericordioso do samaritano para com o desvalido no caminho. A humanização em saúde, segundo esse esquema, é um “jogo poiético” pelo diálogo e vivência de três termos plesiológicos: sofrimento, comportamento e palavra. A humanização refere-se como "fenomenologia poiética" na vida clínica, em que a relação médico-doente é, no seu existir poético, "apelação plesiológica” (Lc 10,28). A parábola do desvalido no caminho é ética de encontro com o samaritano, que se revela como plesiologia teológica. A humanização em saúde, segundo a leitura de W. James, é uma relação entre "mim" (do mim material, social e espiritual), do doente e do médico. Aquele "mim", que evidencia a humanização, revela-se no "mim espiritual". Assim, o "mim" espiritual, na relação médico-doente, é um proprium plesiológico, porque alimenta e fundamenta o "mim" social e o material. 
Naturalmente, a vida empírica da humanização centra-se na relação plesiológica dos três "mim". A humanização tem uma vida própria no "mim" espiritual.

\section{Referências}

ALCÂNTARA, J. A. Como educar a auto-estima. Lisboa: Edições Técnicas, 1997.

BOLANDER, V. B. Enfermagem fundamental: abordagem psico-fisiológica. Rio de Janeiro: Guanabara, 1986.

HATTIE, J. Self-concept. Hillsdade: Lawrence Erlbaum Associates, 1992.

KENDLER, H. H. Introdução à psicologia. Lisboa: Gulbenkian, 1985. v. II.

JAMES, W. Principles of psychology. Toronto: York University, 1890.

JAMES, W. Self concept. Hillsdade: Lawrence Erlbaum Associates, 1992.

SERRA, A. V. O inventário clínico do autoconceito. Psiquiatria Clínica, v. 7, n. 2, p. 54-68, 1986.

Recebido: 25/01/2011

Received: 01/25/2011

Aprovado: 10/02/2011

Approved: 02/10/2011 